\section{AFP: LA DIFÍCIL TAREA DE COMPARARLAS}

El sistema de administradoras de fondos de pensiones (AFP) requiere de la competencia entre los oferentes del servicio. En este yarco, se desenvuelve bajo gran incertidumbre. No es fácil para la

gran mayoría de los ciudadanos comprender dicho sistema. Llama la tención los esfuerzos que tanto cada AfP como la asociación que su puesta en marcha. Considerando los niveles de alfabetización financiera de la población, la comparación entre AFP es casi imposible para la mayoria de los usuarios'

Diariamente recibimos noticias sobre distintos indicadores y publicidad del desempeño de los fondos de pensiones y sus administradoras: estadisticas oficilas mes a mes, columnas en los medios de prensa, etc. Se suma, que al final de toda esta publicidad, además nos señalan que esos indicadores no garantizan nada respecto a esempeño futuro.

La pregunta obvia es ccómo entregar un indicador lo más simple posible al cual las personas puedan acudir en forma rápida, especialmente para aquellos que evaluan cambiarse de AfP? En esa búsquea se enmarca esta column

Las dimensiones a considerar no son muchas. La primera es uno se pregunta jla rentabilidad de qué fondo? E En qué horizonte temporal :el último año dos años, desde el comienzo del sistema? iY si justo el plazo que considero coincide con un periodo en el cual administradora hizo un muy buen trabajo o uno muy malo, pero eso no refleja su historia?

La segunda dimensión son las comisiones. En cada periodo de co作 alguin momento también existieron fijas (en pesos, independientes
del monto cotizado). Hay además otras comisiones y gastos que los usuarios del sistema deben soportar, pero que son de uso esporádico.
Pablo González, Ph.D. in Economics Texas A\&tM University Pez Romero - Ingeniero Comercial Mención Economia FEN UAH.

La tercera dimensión tiene que ver con la calidad de servicio. En

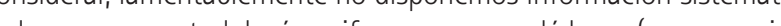
ió un intento de parte de la Superintendencia que fiscaliza dicho sistema.

¿Qué hacemos para responder nuestra pregunta? Construimos tres indicadores sinteticos basados en cierta forma en a rentabilidad pero cada uno con una particularidad y considerando cada AFP desde el comienzo de su existencia launque hubiera cambiado de grupo controlador, hubiera surgido de una fusión o hubiera absorbido a un que ya no existe). Es decir, para cinco de las actuales AFP la historia se

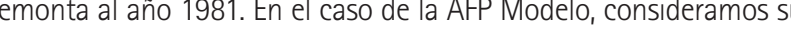

Es complicado comprender tantos indices de rentabilidad, por lo cila cos to intos fondos no calar la asignacion de sus ahoros entre los disces a sus activos Hemos procedido a calcular entonces un indieador de a que tiene bajo su custodia, ponderando obviamente por el tamaño de cada uno de los fondos.

Nos planteamos entonces la siguiente pregunta: ¿cuánto dinero hubiera tenido que depositar en la AFP en junio de 1981 para obteer equivalente a $\$ 10.000$ en setiembre de 2010², considerando las des reales que mes a mes observaron las administradoras?

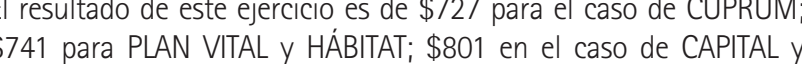
$\$ 819$ en PROVIDA. En este sentido, CUPRUM tuvo el mejor desemeste aspecto, en el cual existe una gran cantidad de indicadores tanto elaboramos un solo indice que pondera los rendimientos de peño durante los casi 30 primeros años de existencia del sistema, considerando únicarealizó con los recursos de los afiliados: nealiz con los recursos de los afiliados: era necesario

iY desde septiembre de 2010 a a fechas ya consun septientre de 2010 a la fechas. ya con un suevo actor en el mercado y desperiodo hay que considera la inn? En este global en los mercados financiers que se global en los mercados financieros, que se por el sistema en promedio que descienden sustancialmente respecto a sus niveles históricos ubicados en torno al $8 \%$ anual. Los $\$ 10.000$ de septiembre de 2010 serian hoy en día $\$ 13.060$ en MODELO; $\$ 12.869$ en HÁBITAT; \$12.678 en CUPRUM; \$12.498 en CAPITAL; $\$ 12.416$ en PLAN VITAL y $\$ 12.364$ en PROVIDA. La diferencia máxima, en un periodo poco mayor a los 7 años, ha sido de un $5,63 \%$ aproximadamente.

El segundo punto al cual atendemos trat de responder al hecho de que es posible que una AFP obtuviese, por ejemplo, un pobre resultado global en un breve periodo y que afecto sus fondos de inverion may negatcomportamiento general Uno podria pensar también en una buena performance sób basada en un golpe de suerte. Para hacernos cargo de este punto, construimos un indicador que mes a mes hace un ranking de cad una de las AFP en base a su rentabilidad. La idea es ver cuántas veces, por ejemplo, es la primera mejor en rentabilidad, la segunda, la tercera, etc. El indice obtenido es un aproximación a la regularidad con la cual se comporta la A.P en comparacion a sus competidoras. Asi, considerando que en la actuallad contamos con seis administradoras, si una Afp hubiera tenido siempre el mejor igual a 6 mientras si una de ellas hubier sido siempre a peor en rentabilidad mubier tendría un valor de 1 en el indicador. Aunque no hay diferencias sustanciales entre unas otras, si se observa regularidad. La evidencia que encontramos habla de 3 grupos relativamente definidos. HÁBITAT y MODELO ubicándose en mejor posición, un segundo grupo en el cual se posicionan CUPRUM Y CAPITA y finalmente PLAN VITAL $y$ PROVIDA. El grafico muestra la evolución de dicho índice a largo del tiempo.

Los indicalos anteriores pueden dor

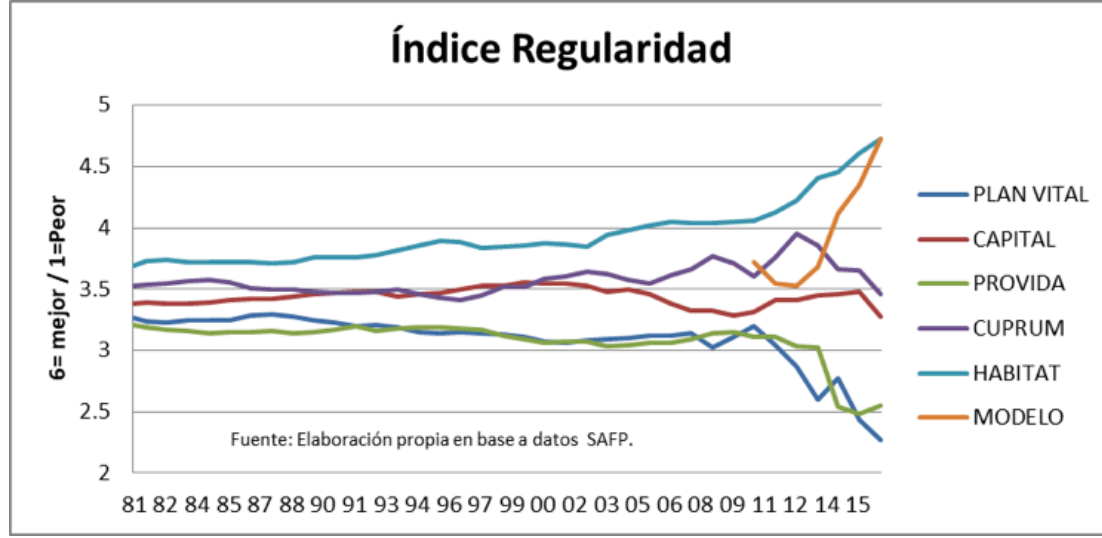

una idea de cómo se desempeña cada administradora al momento de hacer rendir los horros de los cotizantes, pero no tienen en derar las comisie implica cada una. Consiy por lo comisiones no es un tema senciilo parecer arbitraria. En este trabajo el procedimiento consistió en:

- Consideramos que una persona, desde el año 1981 realizó sistemáticamente un aporte en pesos equivatente a 1 UF det periodo coondiente.

- Estimamos el valor de lo acumulado por esta persona a lo largo de su vida conusadara

- El mismo procedimiento utilizamos, pero cada mes, el afiliado depositaba también e equivalente a la suma de la comisión fija y de la comisión variable.

- Finalmente el ratio entre ambas series nos aproxima qué porción de los recursos puestos en el sistema, sea por cotización por comisiones
nos del cotizante.

En laszo comisiones su indice, seria AuP no cobrara plicando que no tomó recursos del afiliado. Este ejercicio, a noviembre del presente año posiciona a MODELO como aquella más favorable en función de rentabilidad $y$ costo $(79,63)$, favorecida probablemente por su corta historia, pero mostrando una tendencia a converger hacia los niveles del resto del sistema. El resto se posiciona en el siguiente orden: HABTAT $(73,22)$, PROVIDA $(72,27)$ CUPRUM (72,26), CAPITAL (71,72) y finalmente PLAN VITAL (69,70). A este respecto, es años los bajos rendimientos de las inversio-

es que realizan los fondos de pensiones han implicado un deterioro general de este a a as en las comisiones en promedio en los

La tarea de comparar un servicio como el prestado por las AFP no es sencilla. Este ese sentido presententa tres contriburir ene sentido presentando tres métricas citerio de ponderación para ellos Si bien vilan a rentabilidad ofrecen miradas distintas. El primero, sólo observando conjunto de las decisiones de inversión ene hacen las administradoras. El segundo, enfocado en su regularidad, y el tercero iniciendo la dimensión de los costos po con

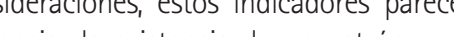
政enciar la existencia de un patrón en

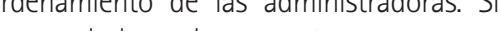
gar a dudas, volver a contar con una evaLación cualititiva de la calidad del servicio podrá contribuir a identificar la opción más perion andos indiedores, begir perotros alternativos que en forma resumida a de fuerte impacto para la sociedad $y$ un umento de la competencia en el sistema.

Un simple test al respecto: ¿ ¿uántas personas estarian en condiciones de explicar quée es el valo cuota de un fondo?

. stuales administradoras existian no todas las S el sistema, para las otras cinco AFP es posible reconstruir sus historias hasta 1981 a 